\title{
Enseñar español en la escuela primaria: autoconfrontación y análisis de la práctica
}

\section{Teaching Spanish in primary school: Self-confrontation and analysis of practice}

\author{
Blanca Araceli Rodríguez HeRnÁndez*
}

El objetivo del trabajo es analizar la práctica de una profesora al enseñar español en una escuela primaria rural mexicana a partir de procesos de autoconfrontación simple. Como herramienta metodológica, esta autoconfrontación permite generar reflexiones desde la propia acción mediante el diálogo y la observación de grabaciones de clase. Con base en las dimensiones para el estudio del trabajo propuestas por el interaccionismo sociodiscursivo, se analizan las relaciones entre el trabajo prescrito, real y representado que la profesora verbaliza en las autoconfrontaciones. Los resultados muestran que las reflexiones giran en torno a cómo relacionar el trabajo prescrito en el currículo con las condiciones reales de su aula. Además, revelan que las prospectivas de la práctica se orientan a mejorar lo observado en las clases. Las conclusiones destacan los retos y las posibilidades de la autoconfrontación al estudio empírico de las prácticas docentes.

The objective of the present work is to analyze the teaching practice of a teacher when teaching Spanish in a rural Mexican primary school based on simple self-confrontation processes. As a methodological tool, simple self-confrontation allows to produce reflections from one's own action, and through dialogue and observation of class recordings. From the dimensions proposed by socio-discursive interactionism, for the study of work, the relationships between prescribed, real and represented work that the teacher verbalizes during self-confrontations are analyzed. Results show that reflections verbalized by the teacher address the way of linking prescribed work in the program with real conditions in her classroom. Furthermore, they reveal that the prospective of her practice aim to an improvement of what was observed during classes. The conclusion addresses more generally the challenges and possibilities of self-confrontation to the empirical study of teaching practices.

\author{
Palabras clave: \\ enseñanza de la \\ lengua materna, \\ análisis de la \\ práctica, práctica \\ docente, estudio \\ del trabajo, \\ enseñanza del \\ español
}

\section{Keywords:}

teaching the mother tongue, analysis of practice, teaching practice, work study, teaching Spanish

Recibido: 11 de enero de 2021 | Aceptado para su publicación: 17 de junio de 2021|

Publicado: 15 de julio de 2021

Cómo citar: Rodríguez Hernández, B. A. (2021). Enseñar español en la escuela primaria: autoconfrontación y análisis de la práctica. Sinéctica, Revista Electrónica de Educación, (57), e1258. https://doi.org/10.31391/S2007-7033(2021)0057-005

\footnotetext{
* Doctora en Pedagogía por la Universidad Nacional Autónoma de México. Profesora en la Facultad de Psicología de la Universidad Autónoma de San Luis Potosí. Coordinadora de la licenciatura en Psicopedagogía de la misma universidad. Pertenece al Sistema Nacional de Investigadores, nivel I. Líneas de investigación: didáctica de las lenguas y formación docente. Correo electrónico: araceli.rodriguez@uaslp.mx/https://orcid.org/0000-0001-8876-7502
} 


\section{INTRODUCCIón}

egún la perspectiva tecnocrática para el estudio de la práctica docente, la función del profesor se reduce a la ejecución de tareas y ejercicios de enseñanza prescritos, por lo que su actividad y pensamiento no son reconocidos ni considerados como objetos de análisis (Pérez-Gómez y Gimeno, 1988). Desde hace casi cuatro décadas, investigaciones encabezadas por Jackson (1968), Schön (1987) y Stenhouse (1982) plantearon un cambio conceptual en la forma de concebir al maestro, que consistió en definirlo como sujeto reflexivo, racional, que toma decisiones, emite juicios, construye creencias y crea rutinas propias de su desarrollo profesional (Pérez-Gómez y Gimeno, 1988; Serrano, 2010). En consecuencia, el enfoque epistémico para estudiar las prácticas docentes se amplió y los trabajos comenzaron a centrarse en el pensamiento del profesorado, lo que derivó en nuevos métodos de investigación.

Desafortunadamente, las investigaciones que estudian el pensamiento del profesor no forman un cuerpo sistemático y acumulativo de conocimientos sobre el tema (Serrano, 2010). Un ejemplo de lo anterior son las diferentes maneras de acercarse a este y referirlo: creencias, decisiones, saberes, teorías implícitas, representaciones y trabajo representado, por mencionar algunas. Como antítesis de esta diversidad, y a nuestro juicio, los objetos de investigación parecen orientarse hacia el pensamiento del profesor a partir de su discurso (el decir de los maestros sobre su práctica), por un lado, y a partir de la acción (las interacciones de clase y el aula como espacio de investigación), por otro. A continuación, presentamos los trabajos que se ubican en alguno de estos grupos.

Las investigaciones que estudian el pensamiento del profesor desde el discurso utilizan entrevistas, cuestionarios, autoinformes y escalas Likert como técnicas para explorar el decir de los maestros, y se orientan por enfoques epistemológicos como la psicología piagetiana, la teoría de la mente y las teorías cognitivas (Contreras, 2008). Como parte de los objetos de estudio, exploran las creencias acerca del aprendizaje (Badiola y Ruiz, 2013; Serrano, 2010) y el currículo (Contreras, 2008), las teorías implícitas sobre la alfabetización inicial (Añorve, 2013) y el conocimiento teórico sobre la enseñanza de contenidos disciplinares como el español (Clemente, Ramírez y Sánchez, 2014; Rodríguez y Clemente, 2013; Rodríguez, 2017). En conjunto, los resultados de estos trabajos aportan a la conceptualización de los maestros como sujetos sociales que no solo ejecutan acciones, sino que construyen y reconstruyen significados sobre lo que hacen.

Respecto a las finalidades de las investigaciones, algunas estudian el pensamiento del profesor como un fin en sí mismo; es decir, con la intención de profundizar en lo que piensan los maestros sobre temáticas relacionadas con la enseñanza y el aprendizaje. Sin embargo, otras, de este mismo grupo, abordan ese pensamiento para contribuir a la comprensión de las prácticas docentes. Estas últimas han mostrado que hablar sobre la práctica no siempre la describe; algunas veces es más una defensa o racionalización de ella. Montes, Caballero y Miranda (2017) proponen estudiar la concreción de la práctica, porque ahí convergen la planeación y la reflexión, lo que brinda mejores insumos para analizar el trabajo de los maestros. 
Las investigaciones ubicadas en el segundo grupo estudian el pensamiento del profesor a partir de la acción observada en el aula. Para recuperar las acciones de los docentes, utilizan estrategias metodológicas como el visionado de clases, la evocación y el recuerdo. Estas estrategias desencadenan procesos de toma de conciencia que se traducen en verbalizaciones explícitas sobre la actividad para reflexionar sobre ella (Ruiz-Bikandi y Camps, 2007; Ruiz-Bikandi, 2007; Plazaola y Ruiz, 2012; Plazaola, Ruiz e Iriondo, 2018; Goigoux, 2010; Edelstein, 2011). Para estos trabajos, el pensamiento del profesor es un medio para conseguir un fin mayor: comprender las prácticas docentes.

Ahora bien, una finalidad que subyace al estudio de las prácticas es la formación del profesorado. Los trabajos que se orientan hacia dicha finalidad (Ruiz-Bikandi, 2007; Ruiz-Bikandi y Camps, 2007; Plazaola y Ruiz, 2012; Plazaola, Ruiz e Iriondo, 2018; Goigoux, 2010; Esteve, Caradell y Farró, 2012; Edelstein, 2011) comparten una premisa: la reflexión después de la acción modela la acción futura de los profesores (Esteve, Carandell y Farró, 2012), lo que puede incidir positivamente en la mejora de sus prácticas.

Como parte de los trabajos de la red Hiprest (Formación del Profesorado para la Enseñanza de las Lenguas en el País Vasco), diferentes investigaciones utilizan la autoconfrontación dentro de los modelos formativos de docentes, que pone en primer plano la actividad de enseñanza (Ruiz-Bikandi, 2007; Plazaola y Ruiz, 2012; Plazaola, Ruiz e Iriondo, 2018); es decir, el profesor observa las imágenes de su práctica para analizarla a partir del diálogo con un agente externo. Las investigaciones al respecto muestran que esta herramienta metodológica ayuda a reflexionar sobre las prácticas sin el peso de la actividad y a través del diálogo con otros.

Como parte de los trabajos desarrollados en Ginebra, Goigoux (2001) retoma los aportes de la ergonomía y la teoría de la actividad para utilizar el visionado de clases en el estudio de las prácticas de profesores con experiencia. La intención de estos trabajos es esclarecer el saber práctico del experto para compartirlo con profesores más jóvenes mediante instrumentos didácticos que los ayuden a orientar sus decisiones didácticas.

En resumen, las investigaciones referidas en este último grupo sostienen que el profesional se forma pensando desde su práctica: revisando lo que hace, preguntándose sobre ello y cuestionando el proceso de adquisición de aprendizajes de sus estudiantes (Ruiz-Bikandi y Camps, 2007). No obstante, también plantean una discusión en torno al método. Para autores como Bronckart (2007), la reflexión por sí sola no produce desarrollo, por lo que, para incidir en la acción futura de los docentes, se requieren mecanismos cuidadosos que acompañen el visionado de las imágenes y desencadenen procesos de análisis que sobrepasen la autocontemplación y defensa de las prácticas.

Situando la discusión en el contexto mexicano, los profesores de educación básica cuentan con escasos espacios para reflexionar a partir de sus prácticas. Las jornadas de trabajo en las escuelas públicas se restringen a la estancia frente a grupo. De este modo, el trabajo y el salario del maestro no prevén la reflexión sobre las clases. Estas condiciones laborales se intensifican cuando los profesores trabajan en contextos rurales. En estas localidades hay menos maestros en las escuelas y las condiciones geográficas en que se ubican los centros hacen que las distancias entre estos y los hogares de los profesores sean largas y las rutas de acceso, escasas. Ambas carac- 
terísticas hacen que las condiciones institucionales que podrían incentivar el trabajo colaborativo para reflexionar la práctica se desdibujen todavía más que en las escuelas urbanas. Aunado a ello, las realidades docentes en contextos rurales han sido escasamente consideradas en la investigación educativa en México (Rebolledo y Torres, 2019).

Estas condiciones en que trabajan los profesores mexicanos repercuten en al menos dos áreas. La primera y más obvia es el trabajo entre pares. Los profesores no cuentan con espacios formales integrados a la jornada laboral para discutir con sus colegas sobre sus prácticas, de ahí que las posibilidades de pensar en forma colaborativa sobre lo que se hace y cómo se hace son reducidas. La segunda está relacionada con el conocimiento de la práctica docente como objeto de estudio; esto es, el aula se convierte en una realidad de difícil acceso para el investigador, quien recupera las acciones que observa, pero difícilmente accede al pensamiento del profesor acerca de lo realizado.

Teniendo en cuenta estas carencias, este trabajo pretende aportar evidencias al campo de conocimiento de las prácticas docentes al retomar el pensamiento del profesor a partir de la observación y el diálogo sobre su práctica. El objetivo es analizar la práctica docente de una profesora al enseñar español en una escuela primaria rural mexicana desde procesos de autoconfrontación simple para generar la reflexión con base en su propia acción. Para lograrlo, recurrimos a un enfoque de investigación didáctica orientado al estudio del trabajo del profesor o profesora en el marco de las mediaciones entre los alumnos y un contenido específico, en este caso, la lengua.

El propósito esencial de nuestro estudio es comprender la práctica de la profesora tomando en cuenta sus reflexiones sobre lo realizado para profundizar en el análisis de la enseñanza del español en contextos rurales. Estas reflexiones pueden ocasionar efectos positivos en el trabajo de la docente, que no son parte de los objetivos de investigación y, por lo tanto, no se consideran para el análisis.

\section{REFERENTES TEÓRICOS PARA ANALIZAR LA PRÁCTICA}

La unidad de análisis de este trabajo se circunscribe a las relaciones entre el profesor y un grupo de alumnos acerca de un saber específico: la lengua. Para profundizar en ello, retomamos el interaccionismo sociodiscursivo (en adelante ISD) como perspectiva teórica enfocada en la didáctica de las lenguas (Bronckart, 2007, 2013; Riestra, 2008, 2014). El ISD analiza el lenguaje, el pensamiento y la actividad humana a partir de los postulados teóricos de la psicología del desarrollo desde los aportes de Vigotsky y la lingüística, desde autores como Saussure, Voloshinov y Coseriu.

Una de las áreas de investigación del ISD es el trabajo docente. Bronckart (2007) define la enseñanza como el verdadero trabajo del profesor; por ello, en este texto hablamos del trabajo del profesor para referirnos a sus prácticas de enseñanza. El ISD retoma los aportes de la teoría de la actividad (Leontiev, 1984) en dos sentidos: para conceptualizar el trabajo docente y definir las consignas de enseñanza en cuanto forma de acceder a lo que sucede en el aula.

El trabajo docente desde el ISD

El trabajo es una actividad gobernada por motivaciones, finalidades y normas colec- 
tivas mediatizadas por el lenguaje. En el trabajo del profesor, estas tres se encuentran estrechamente relacionadas con los objetos de saber movilizados en cada clase. De ahí que el ISD se trate de un enfoque de investigación didáctica centrado en la enseñanza de las lenguas en espacios escolares.

Para estudiar el trabajo del profesor, el ISD propone tres dimensiones: trabajo prescrito, trabajo real y trabajo representado (Bronckart, 2007). La primera refiere a la prescripción de lo que debería ser y está registrada en los documentos que orientan la actividad de enseñanza. Esta dimensión se plasma por escrito y es posible acceder a ella a través de la lectura de los documentos. En el caso de México, el trabajo prescrito se encuentra en los materiales oficiales que la Secretaría de Educación Pública (SEP, 2017) proporciona de forma gratuita a profesores y alumnos de primaria. Las planificaciones de clase que realizan los profesores pueden retomar el material oficial, o no.

El trabajo real, por su parte, es la actividad del profesor en el aula, es decir, lo que se realiza en clase, que se observa en las interacciones entre el maestro y los estudiantes. Por su carácter eminentemente oral, es posible acceder a este a través de la grabación y transcripción de las interacciones de clase.

Por último, el trabajo representado es lo que está implícito en las acciones del profesor y que solo él conoce. Las formas de acceder a este trabajo pueden ser las entrevistas semiestructuradas (Riestra, 2008), o bien, el visionado de clases acompañado del diálogo con agentes externos (Goicoechea, Riestra y Vodnik, 2011).

En conjunto, las tres dimensiones propuestas por Bronckart (2007) recuperan la riqueza del trabajo docente a la luz de lo que se pretende hacer y desde la reflexión del profesor sobre sus propias acciones.

\section{Las consignas de enseñanza en el análisis del trabajo docente}

Basada en el ISD y con fundamento en la teoría de la actividad, Riestra (2008) concibe las consignas como los enunciados elaborados por los docentes para comunicar a los alumnos qué hacer y cómo hacerlo. Las consignas y sus efectos se han estudiado con base en lo que los alumnos dicen o escriben durante la clase (Goicoechea, Riestra y Vodnik, 2011). Los resultados de estos trabajos se han utilizado con fines de formación docente en diferentes investigaciones emprendidas por el grupo de trabajo encabezado por Riestra en Argentina.

Riestra $(2008,2014)$ distingue entre consignas en sentido estricto y en sentido amplio. Las primeras son segmentos de textos que definen e inician la actividad producida mediante la clase (Riestra, 2014); se trata de instrucciones que brinda el profesor a los aprendices. Las consignas en sentido amplio, por su parte, son las producciones verbales de los profesores que encuadran y comentan las primeras (Riestra, 2014), porque las reformulan para interactuar con los alumnos. El estudio de las consignas permite acceder al trabajo real en cuanto actividad mediatizada por el lenguaje en las interacciones de clase. En esta investigación, el estudio de estos segmentos de actividad conforma el momento previo a la autoconfrontación, pues ayuda a la investigadora a orientar las preguntas y centrar el diálogo con la profesora. 


\section{La autoconfrontación simple}

La autoconfrontación es una herramienta para analizar la actividad del profesor (Goigoux, 2001, 2010) que permite acceder al trabajo representado. Se trata de un análisis in situ de las prácticas de enseñanza en las cuales el profesor se confronta con lo sucedido en su aula a partir del video y dialoga sobre ello con el investigador. Este proceso de diálogo ayuda a identificar los sentidos que atribuye el maestro a su trabajo y analizarlos para conocer sus intenciones y aprehender mejor su pericia profesional (Goigoux, 2001).

Durante la autoconfrontación, la voz del profesor observado permite conocer los problemas que enfrentó, cómo los solucionó y cómo se sitúa frente a la posibilidad de cambio que ofrece la reflexión sobre la acción observada en las imágenes. En este proceso, el papel del investigador es indispensable porque su función es sugerir los espacios para la reflexión y apoyar al profesor en la comprensión de lo observado. Sin la debida precaución metodológica, estos procesos de reflexión sobre la acción corren el riesgo de convertirse en lo que anticipa Bronckart (2007): una suerte de autocontemplación inútil.

\section{MÉTODo}

La investigación se ubica en el paradigma cualitativo y retoma los aportes del enfoque interpretativo de la fenomenología en tanto busca conocer los significados que los individuos dan a su experiencia (Rodríguez, Gil y García, 1999, p. 42). En específico, se trata de una profesora que, con base en el visionado de sus prácticas docentes, verbaliza su pensamiento a partir de la acción. En este marco de ideas, la pregunta que orientó el trabajo es ¿qué reflexiones, a partir de su práctica al enseñar español, expresa verbalmente una profesora de primaria?

Según Izcara (2014), la investigación cualitativa busca estudiar un número reducido de casos para comprender un hecho o fenómeno social. Para ello, el muestreo para la selección de los casos posee un carácter intencional. En esta investigación, los criterios de selección de la participante fueron: ser profesora de primaria, laborar en una zona rural y tener compromiso para participar en las diferentes etapas del trabajo.

\section{Contexto}

La profesora participante estudió la licenciatura en Educación Primaria en una normal pública y, al momento de la recolección de datos, tenía dos años de servicio. La escuela en la que labora es su segunda adscripción y se ubica en una localidad perteneciente al municipio de Zaragoza, en el estado de San Luis Potosí, México. Previamente, trabajó en una institución de contexto rural alejada de la capital del estado, por lo que vivía en la localidad y viajaba cada quince días a su casa. La escuela actual está más cerca; por ello, puede ir y venir todos los días.

La localidad donde se sitúa la escuela tiene una población de 500 habitantes. De acuerdo con la Secretaría de Desarrollo Social (Sedesol, 2013), su índice de margi- 
nación es de - 0.52 , lo que se traduce en un grado de marginación alto, y el índice de rezago social es bajo (Sedesol, 2013). La institución es una primaria de organización completa que, en el ciclo escolar 2019-2020, atendió una matrícula de 119 alumnos (59 mujeres y 60 hombres) distribuidos en seis grados. Dispone de seis docentes, uno por grado, y un director sin grupo, según datos del Sistema de Información y Gestión Educativa (2018). La profesora atiende el grupo de quinto, el cual se compone de 25 alumnos, 16 mujeres y 9 hombres.

\section{Diseño de la investigación}

El diseño de la investigación se realizó en dos etapas denominadas A y B, que sucedían de forma casi simultánea. La A consistió en la recolección de datos en el aula; se hicieron grabaciones en audio y video de las clases de español, así como observaciones no participantes. Una observadora (distinta a la investigadora) permaneció dos meses en el aula. Las primeras dos semanas familiarizaron a los alumnos con la videocámara y la presencia del agente externo. La función de la observadora era encargarse del equipo de grabación (prenderlo, moverlo cuando fuera necesario, verificar que estuviera grabando y apagarlo), tomar notas de las actividades de la profesora -sobre todo de aquellas que podrían escapar del video- y consultar la planificación de la maestra para registrar los objetivos de enseñanza de las clases observadas.

En esta etapa se grabaron 22 sesiones de clase con una duración de entre 40 y 80 minutos cada una. En suma, se transcribieron 21 horas de grabación. El propósito de las transcripciones fue proporcionar un panorama completo de lo sucedido en clase y del trabajo prescrito para cada sesión. Para elaborarlas, primero se registraban los objetivos de enseñanza obtenidos de la planificación de la maestra y, luego, se transcribían las interacciones de clase.

La profesora efectuó sus planificaciones didácticas orientándose por los objetivos de enseñanza propuestos en el currículo. A partir de los materiales curriculares, obtenía los aprendizajes esperados y las prácticas sociales del lenguaje. Los primeros señalan lo que se espera que aprendan los estudiantes en determinado periodo durante el ciclo escolar, mientras que las segundas son modos de interacción con el lenguaje que enmarcan la producción e interpretación de textos orales y escritos (SEP, 2017).

En esta etapa también se realizó la preparación de la investigadora para las autoconfrontaciones. Antes de cada autoconfrontación, se leyeron las transcripciones de las clases grabadas en esa semana para identificar el objetivo de enseñanza (trabajo prescrito) y señalar las consignas en sentido estricto y amplio que estuvieran acompañadas de reacciones orales de los estudiantes: respuestas a ejercicios de clase, socialización de ejercicios en el grupo, dudas, preguntas o comentarios expresados a la maestra.

Posteriormente, se colocó la información en una tabla junto con la codificación de la transcripción (número de sesión y una referencia a la práctica social del lenguaje abordada) (ver tabla 1). Para la transcripción de las interacciones de clase, se utilizó el siguiente código: MA para las intervenciones de la maestra; las primeras dos iniciales del nombre para marcar las intervenciones de los estudiantes; comillas " $\mathrm{xxx}$ " para señalar los fragmentos de lectura en voz alta; puntos suspensivos xxx... para pausas largas; y paréntesis (xxx) para introducir señalamientos o aclaraciones. 
Este momento previo a la etapa B contribuyó a elegir la sesión de clase para desarrollar cada autoconfrontación.

Tabla 1.Identificación de consignas en el trabajo real

\begin{tabular}{|c|c|c|}
\hline $\begin{array}{l}\text { Código de } \\
\text { transcripción }\end{array}$ & Consigna en sentido estricto & Consigna en sentido amplio y reacciones de los estudiantes \\
\hline S1_Refranes & $\begin{array}{l}\text { Vas a leer uno de tus refranes } \\
\text { que encontraste, pero que no } \\
\text { sea tuyo, que te hayas que- } \\
\text { dado con uno que escribió tu } \\
\text { compañero, y darme un ejem- } \\
\text { plo de una situación donde tú } \\
\text { aplicarías ese refrán }\end{array}$ & $\begin{array}{l}\text { Al: ¿Cómo, maestra? } \\
\text { MA: Me vas a leer tu refrán y me vas a decir una situación don- } \\
\text { de puedes aplicar ese refrán, ese refrán que no es tuyo, que es } \\
\text { de alguno de tus compañeros con los que estuviste } \\
\text { (Algunos niños comentan que el refrán que tienen es el que } \\
\text { ellos mismos escribieron) } \\
\text { MA: Bueno, como varios se quedaron con el suyo, no hay } \\
\text { problema, lo importante es que vayas pensando... te voy a dar } \\
\text { unos segunditos para que le pienses y luego lo compartas... } \\
\text { Ahora sí, ¿quién ya lo tiene? } \\
\text { Li: "Marrano que se duerme, buenas noches le quedan” } \\
\text { MA: ¿Qué querrá decir ese refrán o en qué situación lo aplica- } \\
\text { rías tú, Lizet? } \\
\text { Li: Como si a mí se me hubieran caído los dientes, entonces si } \\
\text { yo me duermo me dejan dinero } \\
\text { MA: Mmm, no, de hecho, déjame contarte que ese es un refrán } \\
\text { que yo no había escuchado, vuélvelo a leer, por favor } \\
\text { Li: "Marrano que se duerme, buenas noches le quedan” } \\
\text { MA: La verdad no me suena..., yo creo que me lo voy a llevar } \\
\text { de tarea, nunca lo había oído, } \\
\text { ¿alguien ya lo había escuchado antes? }\end{array}$ \\
\hline
\end{tabular}

En la etapa B de la investigación se llevaron a cabo las autoconfrontaciones entre la profesora y la investigadora. Estas se realizaron cada semana, excepto la semana cinco cuando se canceló a petición de la maestra. En total, fueron cinco autoconfrontaciones con una duración de entre 60 y 90 minutos cada una, que se organizaron en dos momentos. En el primero se invitó a la profesora a observar el video de la clase y elegir libremente sobre lo que quisiera hablar, ya fuera durante la observación del video o al final de este. En el segundo momento, la investigadora orientó la reflexión a partir de tres preguntas que pretendían explorar la dimensión del trabajo representado:

-Objetivos de enseñanza: ¿qué querías enseñar en esa clase?

-Efecto de la enseñanza en el aprendizaje: ¿qué crees que aprendieron los niños en esa clase?

-Prospectiva sobre la práctica: ¿cómo mejorarías la actividad?

En el desarrollo de las autoconfrontaciones estas preguntas se adaptaban a lo observado en cada clase con la intención de hacerlas más específicas para incentivar la reflexión de la profesora. La tabla 2 presenta la organización de lo efectuado en cada etapa. 
Tabla 2. Actividades en cada etapa de la investigación

\begin{tabular}{|c|c|c|}
\hline Semana & Actividades etapa A & Actividades etapa B \\
\hline 1 & Familiarizar a los alumnos con el equipo y la observadora & No hubo \\
\hline 2 & & No hubo \\
\hline 3 & Grabaciones de clases en audio y video & Autoconfrontación 1 \\
\hline 4 & Observaciones no participantes & Se canceló \\
\cline { 2 - 3 } 5 & Transcripción de audios & Autoconfrontación 3 \\
\cline { 2 - 3 } 6 & Análisis de transcripciones & Autoconfrontación 4 \\
\cline { 2 - 3 } 7 & & Autoconfrontación 5 \\
\hline
\end{tabular}

\section{Procedimiento de análisis: autoconfrontaciones}

Optamos por un análisis de contenido en el que exploramos tanto las respuestas a las preguntas del segundo momento de la autoconfrontación (objetivos de enseñanza, efecto de la enseñanza en el aprendizaje y prospectiva de la práctica) como las verbalizaciones a partir de los intereses de la profesora.

Primero, transcribimos los audios de las autoconfrontaciones (410 minutos de grabación). Después, leímos las intervenciones de la profesora para identificar temáticas recurrentes que permitieran conocer su pensamiento sobre lo observado. Por último, sistematizamos la información en una tabla en la que colocamos las dimensiones del trabajo analizadas y presentamos una primera interpretación de los datos con base en las temáticas expresadas en las verbalizaciones de la maestra (ver tabla 3).

Además, incluimos codificaciones para el trabajo real (código de transcripción establecido en la etapa A) y el trabajo representado (por ejemplo, Aut_1 refiere a la primera autoconfrontación; Aut_2, a la segunda, y así sucesivamente). Para la transcripción, utilizamos corchetes [xxx] para marcar las intervenciones de la investigadora y MA, para las de la profesora.

Tabla 3. Sistematización de datos para el análisis

\begin{tabular}{|c|c|c|}
\hline $\begin{array}{c}\text { Dimensión del } \\
\text { trabajo }\end{array}$ & Fuente & Material empírico \\
\hline \multirow{3}{*}{\begin{tabular}{c} 
Trabajo prescrito \\
\cline { 2 - 3 }
\end{tabular}} & Práctica social del lenguaje & $\begin{array}{r}\text { Analizar las características de las fábulas y refranes para esta- } \\
\text { blecer sus semejanzas y diferencias }\end{array}$ \\
\cline { 2 - 3 } & Objetivos de enseñanza & $\begin{array}{c}\text { Identifica las características de fábulas y sus semejanzas y dife- } \\
\text { rencias con los refranes }\end{array}$ \\
& & $\begin{array}{c}\text { Comprende la función de las fábulas y refranes } \\
\text { Interpreta el significado de los refranes }\end{array}$ \\
\hline
\end{tabular}




\begin{tabular}{|c|c|c|}
\hline Trabajo real & $\begin{array}{l}\text { Consignas en sentido es- } \\
\text { tricto, consignas en sentido } \\
\text { amplio y reacciones orales } \\
\text { de los alumnos }\end{array}$ & $\begin{array}{l}\text { S6_Refranes. MA: Vas a inventar una fábula y el refrán que } \\
\text { pensaste va a ser moraleja. Lo primero que tienes que hacer } \\
\text { es pensar en tu refrán favorito, que te gusta y que lo puedes } \\
\text { interpretar o entender y después te vas a inventar una historia } \\
\text { que pueda..., que pueda contener el refrán (camina entre las } \\
\text { filas revisando los trabajos de los alumnos). Algunos niños, de } \\
\text { lo que he leído, metieron su refrán dentro de las fábulas y no } \\
\text { está mal. Algunas veces pusieron que el personaje mencionaba } \\
\text { el refrán como parte de su diálogo. Lo que vamos a hacer es que } \\
\text { si tú hiciste eso vas a escribir aparte la moraleja, ¿de acuerdo?, } \\
\text { aparte de tu..., al final }\end{array}$ \\
\hline $\begin{array}{c}\text { Trabajo represen- } \\
\text { tado }\end{array}$ & $\begin{array}{l}\text { Verbalizaciones de la } \\
\text { profesora en la autocon- } \\
\text { frontación }\end{array}$ & $\begin{array}{c}\text { Aut_2. En ninguna parte está escribir, pero en el libro la ponen } \\
\text { como un producto... [Entonces, esa, la consigna de escribir una } \\
\text { fábula a partir de un refrán, ¿la retomaste del libro?] Sí, en el } \\
\text { libro lo marca como producto... Eso se me hizo raro, porque, } \\
\text { pues..., no va mucho con el propósito. El propósito se queda } \\
\text { hasta las diferencias, pero ya lo escrito está como extra, pero } \\
\text { igual lo hice. [¿Cuándo te diste cuenta de que no venía en los } \\
\text { aprendizajes esperados?] Cuando hice la planeación. [¿Y por } \\
\text { qué lo integraste?] Ah pues porque venía en el libro, ese era el } \\
\text { producto, ahí lo marca }\end{array}$ \\
\hline Interpretación & $\begin{array}{c}\text { Temáticas expresadas en las } \\
\text { verbalizaciones }\end{array}$ & Reflexiona sobre lo prescrito en materiales oficiales \\
\hline
\end{tabular}

Posteriormente, a partir de un análisis inductivo de lo dicho por la profesora (Hernández, Fernández y Baptista, 2014), las temáticas identificadas en cada autoconfrontación se agruparon en dimensiones y categorías de análisis.

Tabla 4. Dimensiones y categorías de análisis

\begin{tabular}{|c|c|}
\hline Dimensiones & Categorías \\
\hline $\begin{array}{c}\text { Los sentidos de las prácticas } \\
\text { observadas }\end{array}$ & Reflexiones sobre el trabajo prescrito en el currículo oficial \\
Tensiones entre el trabajo prescrito y el trabajo real \\
$\begin{array}{c}\text { Las prospectivas sobre prácticas } \\
\text { futuras }\end{array}$ & $\begin{array}{c}\text { Incertidumbre frente al uso del currículo oficial como guía del } \\
\text { trabajo prescrito }\end{array}$ \\
\hline
\end{tabular}

\section{REFLEXIONES QUE VERBALIZA LA PROFESORA SOBRE SU PROPIO TRABAJO AL ENSEÑAR ESPAÑOL}

Los resultados se organizan en dos apartados conforme a cada una de las dimensiones de análisis. El primero da cuenta de las reflexiones de la profesora acerca de las prácticas observadas y pone especial atención en mostrar las tensiones que experimenta entre el trabajo prescrito y el real. El segundo presenta la prospectiva de la maestra sobre su propio trabajo al enseñar español. En conjunto, los dos apartados muestran las reflexiones de la profesora respecto a su propia acción visualizada en las imágenes en el marco de las dimensiones del trabajo del ISD. 
Las reflexiones a partir de la práctica: tensiones entre el trabajo prescrito y el real

La profesora organiza la planificación de clase con base en dos documentos curriculares: el programa de estudios y el libro de texto de español. Los fragmentos de las autoconfrontaciones que se presentan a continuación ilustran las dudas y momentos de incertidumbre ante esos documentos y, a su vez, identifican tensiones entre los trabajos prescrito, real y representado. Para contextualizar las verbalizaciones de la profesora, primero describimos de manera breve la clase observada y, después, mostramos el diálogo de la autoconfrontación.

En la clase observada (Aut_2), los alumnos eligieron su refrán favorito y, luego, inventaron una fábula en la cual ese refrán era la moraleja. El trabajo en la clase se desarrolló individualmente y sin hacer preguntas a la profesora, pero cuando los niños y las niñas leyeron sus fábulas en voz alta, estas no cumplían con lo solicitado. Los textos tenían un refrán y algunas características de la fábula, pero no había moraleja. El refrán no era una enseñanza derivada del texto. La profesora recogió los escritos para revisarlos después de clase y finalizó la sesión.

Luego de observar el video, la maestra habló sobre lo que encontró en la revisión de los textos (una revisión ortográfica principalmente), pero no aludió a lo sucedido en la clase ni a la complejidad de la consigna de escritura que propuso. Ante ello, la investigadora preguntó: “¿Cómo podríamos valorar lo que pasó en esta clase?, ¿cuál era el propósito de la actividad?". La respuesta de la maestra permite advertir sus reflexiones en torno al trabajo prescrito, porque reconoce las incongruencias entre el programa y el libro de texto; pese a ello, sigue la prescripción del libro porque representa el producto de la clase, es decir, el observable indicado en el trabajo prescrito al culminar un cierto periodo de enseñanza:

La práctica social del lenguaje es "analizar las características de las fábulas y refranes para establecer sus semejanzas y diferencias". Los aprendizajes esperados nada más son: identifica las características de fábulas y sus semejanzas y diferencias con los refranes, y comprende la función de las fábulas y refranes, e interpreta el significado de los refranes. En ninguna parte está escribir, pero en el libro la ponen como un producto... [Entonces, esa, la consigna de escribir una fábula a partir de un refrán, ¿la retomaste del libro?] Sí, en el libro lo marca como producto... Eso se me hizo raro, porque, pues..., no va mucho con el propósito. El propósito se queda hasta las diferencias, pero ya lo escrito está como extra, pero igual lo hice. [¿Cuándo te diste cuenta de que no venía en los aprendizajes esperados?] Cuando hice la planeación. [¿Y por qué lo integraste?] Ah pues porque venía en el libro, ese era el producto, ahí lo marca (fragmento de Aut_2).

En otro video (Aut_4), los alumnos compartieron las respuestas a una lista de preguntas de investigación elaboradas previamente. Se trataba de presentar los avances en la producción de un texto expositivo. Después de ver la clase, la profesora consideró que eran buenas preguntas; sin embargo, expresó una preocupación relacionada con el logro de la práctica social del lenguaje prescrita para esa y las siguientes sesiones: ¿cómo ayudar a sus estudiantes a pasar de respuestas cortas a la escritura de un texto expositivo? Para ella, hay una brecha entre los avances y la prescripción del libro que no sabe cómo sortear. Menciona que, para lograr el aprendizaje esperado por el programa, debe apoyarlos con estrategias que complementen las del libro; no obstante, no tiene claro cómo hacerlo:

Me siento un poco confundida al momento de que checo sus preguntas... Son muy buenas sus preguntas, pero hoy que veo algunas, pues sus respuestas son muy directas. 
Por ejemplo, cuánto pesa una ballena y ya ponen pues pesa esto. Entonces..., me causa conflicto pensar cómo ellos ya lo van a escribir, pero a manera de prosa... Eso ya va a estar complicado [0 sea, ¿cómo pasar de una respuesta tan específica y corta a un texto expositivo?] Sí, sí. Bueno, aparte, el texto de por sí es complejo... Para uno podría ser complejo... De hecho, ahorita la siguiente sesión marca ver lo del uso de nexos. Entonces se supone que los nexos ya son para que armen su texto. Pero sí es complejo, no sé cómo pasar de esas preguntas tan concretas a que ya ellos pudieran describir (fragmento de Aut_4).

Posteriormente, en la misma autoconfrontación, la investigadora preguntó: “YY qué modelo de texto expositivo les presenta el libro?". La respuesta deja entrever que conoce bien los materiales prescritos de manera oficial y que hace diferentes aportes a lo que estos proponen. La maestra sabe que los ejemplos del libro de texto no son suficientes para acercar a sus alumnos al objetivo de enseñanza y que ellos solos, sin ayuda, con dificultad podrán acceder a otros modelos textuales. Su contribución al trabajo prescrito tiene la intención de poner en contacto a los estudiantes con diferentes modelos de un género que considera complejo. Ante la gran diversidad de géneros textuales que implica el tipo de discurso expositivo, se necesita claridad sobre el texto que va a enseñar:

En sí yo creo que el libro no marca un tipo de texto. Trae varios ejemplos, en el libro trae como unos cinco ejemplos, pero son textos muy cortitos de qué es un ciclón y también nada más de... descripción. Pero claro, que veas un ejemplo es muy poco ¿verdad?... He metido ya en mis sesiones, les puse un texto de los pingüinos, ese sí traía la imagen y hasta descripción de la imagen, título de la imagen que es algo que pues deben tener. Hoy leímos uno de los nidos y viene varios, este... Y ahí lo que quise que vieran que también los textos pueden tener subtítulos, porque ahí hablan de diferentes nidos de aves... También les llevé una enciclopedia, porque ayer vi lo de los índices. Entonces mi idea era llevarles uno, para que vean cómo se dividen. Me llevé una enciclopedia de Ciencias Naturales. Se las pasé, para que la observaran y la estuvieron viendo. Yo sé que unos se van a ir a buscar en internet la información y ahí quién sabe qué encuentren y el contexto hará que no tengan libros como estos en casa (fragmento de Aut_4).

Al finalizar Aut_2, la profesora expresó una preocupación surgida tanto del análisis de la clase como de lo realizado hasta ese momento para enseñar la práctica social del lenguaje en cuestión: elaborar anuncios publicitarios de productos y servicios de la comunidad para publicarlos. Ella identificó que el programa de estudios no menciona aprendizajes esperados relacionados con las figuras retóricas, por lo cual no incluyó actividades de enseñanza para ese contenido. Sin embargo, en el libro de texto aparece un recuadro de lectura en el que se nombran figuras retóricas; esto es, están en el material de los alumnos, pero no hay orientaciones didácticas para enseñarlas. La profesora manifiesta dudas sobre lo que debe hacer: ¿atreverse a enseñar lo que no viene indicado en el trabajo prescrito oficialmente? 0 bien, ¿seguir la prescripción y no retomar un contenido que podría ser relevante para el texto que se espera que escriban? Esto marca un posicionamiento al respecto sustentado en su "poca práctica":

Me quedó duda en cuanto a lo que mencionan los aprendizajes esperados sobre una parte de las figuras retóricas. Obviamente yo sé que los anuncios incluyen alguna figura retórica, pero ayer que se los di, se los di muy así... superficial, y no lo voy a retomar de nuevo, pero el libro tampoco, no me lo marca. Yo sé que se puede hacer y que indiquemos qué tipo de recurso se está utilizando, pero a mí también se me hace complicado eso de... o sea, de enseñar fuera de lo que no está en el libro, ni en el programa, porque siento que a lo mejor yo sé que eso les está ayudando a los niños, pero también les estoy 
complicando un tema que a lo mejor puede ser más simple para ellos. Me quedé como con la espinita y ahorita lo estaba pensando, porque para mí ya no lo tomaría, por mí están estas figuras retóricas (las del recuadro del libro de texto) y ya las incluyen a veces los anuncios (que elaboraron los niños), ya están ahí. Pero a lo mejor, al momento de revisar los productos (se refiere a los anuncios elaborados por los alumnos) va a salir que realmente se deben tocar y que yo no profundicé en ello. En eso es donde yo digo, pues, entonces ¿qué es lo más conveniente?, ¿lo tomo y desarrollo cada una (cada figura retórica)? A mi poca práctica, las figuras retóricas a veces es más fácil verlas en algún poema, que verlas en un anuncio (fragmento de Aut_2).

\section{Las prospectivas sobre sus prácticas: del trabajo real al trabajo proyectado a futuro}

En las sesiones de autoconfrontación también identificamos reflexiones que expresan posibilidades y alternativas de cambio para mejorar lo que advertimos en los videos.

En la clase observada (Aut_1), la actividad de cierre fue armar dos figuras con las características de la fábula y el refrán: construir una estrella solo con las palabras que describieran a la primera y otra para explicar el segundo. En el desarrollo de la actividad, observamos que los alumnos tuvieron muchas dificultades para entender qué debían hacer y para decidir a qué texto pertenecían dos características: corto y autor. En el diálogo, la profesora detalló lo que había pasado, es decir, relató de nuevo lo visto en el video, pero no verbalizó reflexiones sobre ello. Después, a partir de la intervención de la investigadora, refirió por qué se habían confundido los niños y las niñas, lo cual le permitió hablar sobre el trabajo real de otras sesiones. Las dificultades relacionadas con el contenido están en función del conocimiento de los géneros textuales trabajados:

Mi idea era que con la estrellita que les puse en el inicio... En la hoja de trabajo... Traía fábula o refrán, entonces tenían que acomodar los piquitos de la fábula o el refrán, según sean sus características, para formar la estrella. [¿Y cómo les fue en ese ejercicio?] Les costó dos aspectos, esa la de "corto" la ponían... Venía para ponerse en refrán y esa la ponían en fábula y la otra, la del "autor" (ambas), fueron las dos que les costó más. [¿Por qué crees que pasó eso (poner "corto" como característica de la fábula)?] Porque... tal vez yo lo manejé como que era un texto corto. Recuerdo que en la sesión anterior reiteradamente mencioné que la fábula era un texto corto. [¿Y la idea de autor?] Tal vez porque fue algo que no se retomó mucho, tal vez, en el caso del refrán nada más mencionábamos que es algo que se repite de generación en generación, pero nunca se retomó si tienen autor o no (fragmento de Aut_1).

En el video de la Aut_3, los niños y las niñas buscaron definiciones de palabras en el diccionario. La maestra pidió encontrar el significado de las figuras retóricas: comparación, metáfora, analogía e hipérbole. Las definiciones contenían términos desconocidos, lo que complicó la tarea. Algunos niños tuvieron que ampliar la búsqueda a otras palabras y otros copiaban el significado, pero sin reflexionar sobre el sentido. Como cierre de la actividad, la maestra leyó otra definición: "Las figuras retóricas, también llamadas figuras literarias, representan una manera diferente de utilizar el lenguaje. La finalidad de estas figuras es crear un estilo comunicativo más original, más literario" (fragmento de Aut_3). En el diálogo, la profesora compartió la intención de su clase en un afán de justificar lo sucedido: no tenía la pretensión de profundizar en los conceptos. Además, reconoció que podría mejorar la actividad para hacerla más significativa para los niños y las niñas: 
Yo quería como presentárselos rápido, pero no en sí que los identificaran, aunque ahorita ya viendo todo ya se me ocurrieron otras cosas. Hubiera hecho tal vez algo diferente. [¿Cómo qué?] Tal vez como llevarles frases, eslogan o no sé y tal vez que ellos identificaran qué recurso retórico se estaba utilizando. Tal vez hubiera sido algo más interesante. [¿Qué crees que se logró con la búsqueda de las definiciones en el diccionario?] Pues algo muy vago porque, en sí, los niños sólo lo buscan y lo anotan, a lo mejor se les puede quedar el nombre, pero algo así como significativo, pues no en su totalidad (fragmento de Aut_3).

Durante la misma autoconfrontación, la investigadora preguntó ¿qué valoración podía hacer de la definición que leyó a los niños? La maestra reflexionó sobre la pertinencia de definir un concepto usando términos desconocidos: "No sé si fue clara para ellos... Tal vez no del todo porque, para empezar, implícitamente están otros conceptos como lenguaje literal, figuras retoricas..." (fragmento de Aut_3).

En la clase analizada en Aut_4 no todos los niños y las niñas llevaron la tarea: un eslogan. Un tanto desconcertada, la maestra pidió a quienes sí lo presentaron que lo leyeran en voz alta. Después de la lectura, ella parecía todavía más confundida, así que escribió un eslogan en el pizarrón y subrayó una palabra ("Deja que tu bonito aroma hable bien de ti”). Posteriormente, les preguntó “¿qué función tiene la palabra subrayada?". Las respuestas fueron incorrectas, por lo que terminó diciéndoles que se trataba de un adjetivo. Luego, consultaron el libro de texto para leer la definición de "adjetivos" y ver ejemplos de eslóganes que los contenían. En el diálogo, la maestra explicó que su expectativa era que estos llevaran adjetivos para que los identificaran grupalmente. Sin embargo, ninguno de los ejemplos leídos tenía adjetivo. Esto la obligó a cambiar la actividad que tenía planeada. La frase final de la profesora permite suponer que no se sentía a gusto con el cambio: "Es lo que uno hace en el momento":

Yo creo que tuve que hacer eso porque no me imaginé que los (eslóganes) de tarea no iban a llevar todos (adjetivo)... y sí... es cierto, o sea, no todos los eslóganes usan adjetivos. [¿Y de dónde nació el interés por relacionar el adjetivo con el eslogan?] Me guie por el libro, el libro lo marca que vienen adjetivos en los eslóganes. En la clase pasada como que me centré más en adjetivos que en ver el uso de ellos en el eslogan. Y hoy cuando pasamos al uso de ellos en el eslogan, pues resultó que los eslóganes de los niños no llevaban adjetivos. Entonces inventé el eslogan y nos fuimos al libro, o sea, ya cuando uno está ahí (se refiere a la clase) es lo que uno hace en el momento, incluso en el momento uno no está pensando si es lo correcto, o no.

En la misma autoconfrontación, la investigadora preguntó cómo podría mejorarse la actividad. En su respuesta, la maestra propuso otra estrategia para abordar la función de los adjetivos en el eslogan. Sin la inmediatez de la práctica, en el espacio de reflexión que brinda la autoconfrontación, la profesora propone una alternativa para mejorar su trabajo: “[¿Cómo podrías mejorar la actividad?] Tal vez, para empezar, trabajar con más ejemplos de adjetivos, no directo en eslogan, sino en oraciones adjetivas" (fragmento_Aut4).

\section{Discusión}

Basada en el interaccionismo sociodiscursivo, la investigación reportada identifica, desde procesos de autoconfrontación simple, las reflexiones verbalizadas por una profesora de primaria a partir de su práctica al enseñar español. 
Desde la reflexión derivada de las imágenes de su propia práctica y el diálogo con la investigadora, la profesora comparte sus reflexiones en torno a los trayectos entre el trabajo prescrito en el currículo y el trabajo real. Por un lado, expresa que existe flexibilidad curricular, de la que pueden hacer uso los profesores, pero, por otro, verbaliza conflictos y preocupaciones derivados de la intención de seguir un modelo curricular lejano a sus estudiantes y con el que tampoco parece estar de acuerdo.

En el traslado de lo prescrito a lo efectivo, la profesora habla sobre momentos de incertidumbre frente a inconsistencias de los materiales oficiales, falta de claridad en lo que se espera que hagan los profesores y una brecha entre lo que su alumnado logra, o puede lograr, y lo que el trabajo prescrito espera que alcance. Tal como lo demuestran otras investigaciones que estudian las prácticas a partir del visionado de clases (Plazaola y Ruiz, 2012; Plazaola, Ruiz e Iriondo, 2018), los profesores experimentan contrastes entre la planeación de clase y lo que ocurre en el aula. Sin embargo, estos parecen acentuarse cuando se trata del trabajo prescrito impuesto por un currículo estándar como el mexicano.

Para reflexionar sobre el video, la profesora remite a clases que no se observaron, pero que ayudan a comprender las acciones efectuadas más allá del momento específico sobre el cual se dialoga. La verbalización de lo que pasa en esas clases permite identificar los aportes de la maestra al trabajo prescrito. Ella incluye actividades para acercar a los alumnos a lo esperado por el programa y, además, se anticipa, de cierto modo, a lo que establece el libro de texto.

En consonancia con los trabajos que estudian el pensamiento del profesor con base en la acción (Ruiz-Bikandi y Camps, 2007; Ruiz-Bikandi, 2007; Plazaola y Ruiz, 2012; Plazaola, Ruiz e Iriondo, 2018; Goigoux, 2010), esta investigación muestra las reflexiones de la profesora a partir de lo que hace y a la luz de los aprendizajes que pretende lograr. Lo anterior ayuda a que la profesora proyecte situaciones hipotéticas a futuro y describa la forma en que hubiera podido llevar a cabo las actividades o los cambios que podría hacer para mejorarlas. Esta visión crítica y prospectiva de su práctica es identificada como variaciones de la acción a nivel del trabajo próximo (Ruiz-Bikandi, 2007).

Montes, Caballero y Miranda (2017) proponen analizar la concreción de la práctica para profundizar en su estudio, porque ahí convergen planeación y reflexión. Sin embargo, para acceder a esta no es suficiente con estudiar la práctica. Desde un punto de vista metodológico, se trata de dos momentos diferentes que exigen herramientas y procedimientos distintos al investigador para alcanzar la descripción de lo sucedido como la reflexión a partir de la acción (Schön, 1987; Esteve, Carandell y Farró, 2012), y evitar la autocontemplación de las prácticas (Bronckart, 2007). En este trabajo, la etapa previa a la autoconfrontación permitió conocer con anticipación el trabajo prescrito y real, y brindó más insumos para orientar el diálogo con la maestra.

Las investigaciones que han retomado la autoconfrontación como dispositivo de formación docente destacan sus beneficios en tanto insight reflexivo (Plazaola y Ruiz, 2012; Plazaola, Ruiz e Iriondo, 2018). Sin embargo, en condiciones como en las que laboran los profesores de escuelas rurales en México, mostrar a otros el propio trabajo y verlo con una mirada crítica, ajena en cierto modo, no es una tarea sencilla ni inherente a la observación de las imágenes. Es un ejercicio que requiere práctica 
y preparación para afinar las intervenciones del acompañante externo y motivar la reflexión sin perder el diálogo horizontal entre los participantes.

Finalmente, este trabajo utilizó una herramienta empleada en la formación docente con el objetivo de analizar la práctica. Como señalamos en un inicio, no planteamos expectativas de transformación al trabajo de la profesora. No obstante, cobra relevancia citar las palabras de ella al final de todas las autoconfrontaciones porque su reflexión parece orientada a modelar acciones futuras (Schön, 1987; Esteve, Carandell y Farró, 2012):

Lo que uno vive en clase no es realmente una realidad sino hasta que uno se pone a pensar ¿qué realmente hicieron los alumnos? ¿Cómo actúo yo? Porque a veces, en el momento, uno no lo piensa y uno no lo hace tal cual está planeado. Si no hay esa reflexión de qué voy a cambiar no puede haber un aprendizaje ni en los niños ni en nosotros como docentes (fragmento de Aut_5).

\section{CONCLUSIONES}

El aporte de la investigación se orienta en dos sentidos: por un lado, muestra las reflexiones de una profesora al enseñar español, quien verbaliza sus preocupaciones sobre cómo conciliar el trabajo prescrito en el currículo con trabajo en el aula. La profesora no ha tenido acompañamiento pedagógico para pensar sobre su trabajo al enseñar español. A partir de su participación en esta investigación, reflexionó sobre lo que hizo en el aula y planteó alternativas para modificar su práctica docente. Por otro, el aporte se orienta al uso de la autoconfrontación simple como herramienta metodológica en el análisis de las prácticas docentes. La interacción entre la profesora e investigadora, en el marco del visionado de clases, ayudó a que la docente verbalizara lo representado de su trabajo, algo que únicamente ella conocía y, por lo tanto, solo ella podría revelar (Goicoechea, Riestra y Vodnik, 2011). Este resultado, derivado del procedimiento metodológico, contribuye al campo de conocimiento sobre las prácticas docentes porque permite conocer información que, a menudo, queda implícita en las acciones de los profesores observados y, por ende, escapa del análisis de las prácticas.

\section{REFERENCIAS BIBLIOGRÁFICAS}

Añorve, G. (2013). Las teorías implícitas de los docentes normalistas sobre alfabetización inicial. Presentado en el XI Congreso Nacional de Investigación Educativa. México.

Badiola, N. y Ruiz, U. (2013). Las creencias sobre el aprendizaje de lenguas de futuros docentes. Lenguaje y Textos, núm. 37, pp. 63-71. http://www.sedll. org/sites/default/files/journal/las_creencias_dobre_el_aprendizaje_de_lenguas_en_futuros_docentes._badiola_n.pdf

Bronckart, J. (2013). En las fronteras del interaccionismo socio-discursivo: aspectos lingüísticos, didácticos y psicológicos. En Riestra, Tapia y Goicoechea (eds.). Terceras Jornadas Internacionales de Investigación y Prácticas en Didáctica de las Lenguas y las Literaturas (pp. 39-59). Bariloche: Ediciones GEISE. https://archive-ouverte.unige.ch/unige:81364

Bronckart, J. (2007). Desarrollo del lenguaje y didáctica de las lenguas. Buenos Aires: Miño y Dávila. 
Clemente, M., Ramírez, E. y Sánchez, M. (2014). Enfoques teóricos y prácticas docentes en la enseñanza inicial de la lengua escrita. Cultura y Educación, vol. 22, núm. 3, pp. 313-328. https://doi.org/10.1174/113564010804932175

Contreras, S. (2008). Qué piensan los profesores sobre sus clases: estudio sobre las creencias curriculares y las creencias de actuación curricular. Revista Formación Universitaria, vol. 1, núm. 3, pp. 3-11. http://dx.doi.org/10.4067/ S0718-50062008000300002

Edelstein, G. (2011). Formar y formarse en la enseñanza. Buenos Aires, Argentina: Paidós.

Esteve, O., Carandell, Z. y Farró, L. (2012). La construcción guiada de conocimiento en la formación del profesorado: la función mediadora de la interacción desde los distintos niveles de andamiaje pedagógico. En Actas del V seminario. El aula como ámbito de investigación sobre la enseñanza y el aprendizaje de lengua. España: Servicio Editorial de la Universidad del País Vasco. http:// es.scribd.com/doc/190145262/V-Seminario\#scribd

Goicoechea, M., Riestra, D. y Vodnik, V. (2011). Análisis del trabajo docente: las interacciones en las clases de lengua [CD]. En D. Riestra (comp.). II Jornadas Internacionales de Investigación y Prácticas en Didácticas de las Lenguas y las Literaturas (pp. 374-385). San Carlos de Bariloche, Patagonia Argentina: Ediciones Geise.

Goigoux, R. (2010). Les parcours de formation des enseignants débutants. Presses Univ Blaise Pascal.

Goigoux, R. (2001). Lector in didactica. Un cadre théorique pour l'étude de l'activité du maître de lectura, en J. P. Bernié. Apprentissage, développement et significations (pp. 129-153). Pessac: Presses Universitaires de Bordeaux.

Hernández, R., Fernández, C. y Baptista, P. (2014). Metodología de la investigación. México, DF: McGraw-Hill.

Izcara, S. (2014). La praxis de la investigación cualitativa. Guía para elaborar tesis. México: Plaza y Valdés.

Jackson , P. (1968). La vida en las aulas. Nueva introducción del autor. Madrid: Paideia-Morata.

Leontiev, A. (1984). Actividad, conciencia y personalidad. México: Cartago.

Montes, L., Caballero, T. y Miranda, M. (2017). Análisis de las prácticas docentes: estado del conocimiento en DOAJ y EBSCO (2006-2016). CPU-e. Revista de Investigación Educativa, núm. 25, pp. 197-229. https://doi.org/10.25009/ cpue.v0i25.2529

Pérez-Gómez, Á. y Gimeno, J. (1988). Pensamiento y acción en el profesor. De los estudios sobre la planificación al pensamiento práctico. Infancia y Aprendizaje, núm. 42, pp. 37-63. https://doi.org/10.1080/02103702.1988.10822201

Plazaola, I., Ruiz, U. e Iriondo, I. (2018). Análisis de la propia actividad en el practicum: una experiencia formativa. Revista Complutense de Educación, vol. 29, núm. 4, pp. 1169-1183. https://doi.org/10.5209/RCED.54890

Plazaola, I. y Ruiz, U. (2012). La formación del profesorado para la enseñanza de lenguas: un dispositivo innovador y una red de investigación, e U. Ruiz e I. Plazaola (eds.). El aula como ámbito de investigación sobre la enseñanza y aprendizaje de la lengua. V Seminario (pp. 201-214). España: Argitslpen Zerbitzua. http://hdl.handle.net/10810/15256

Riestra, D. (2014). Usos y formas de la lengua escrita. Reenseñar la escritura a los jóvenes. Buenos Aires: Novedades Educativas. 
Riestra, D. (2008). Las consignas de enseñanza de la lengua. Un análisis desde el Interaccionismo socio-discursivo. Buenos Aires: Miño y Dávila.

Rodríguez, G., Gil, J. y García, E. (1999). Metodología de la investigación cualitativa. Granada, España: Aljibe.

Rodríguez, I. (2017). Enseñanza inicial de la lengua escrita: cuándo iniciar la enseñanza y cómo hacerlo. Una reflexión desde las creencias de los docentes. Revista Perfiles Educativos, vol. 39, núm. 156, pp. 18-36. https://doi. org/10.22201/iisue.24486167e.2017.156.58281

Rodríguez, I. y Clemente, M. (2013). Las tareas de enseñanza de la alfabetización inicial en las prácticas docentes. Estudio de caso. Revista Electrónica Interuniversitaria de Formación del Profesorado, vol. 16, núm 1, pp. 41-54. https:// doi.org/10.6018/reifop.16.1.179431

Ruiz-Bikandi, U. (2007). La autoobservación en clase de lengua como mecanismo colectivo de formación. El discurso protector. Cultura y Educación, vol. 19, núm. 2, pp. 165-181. https://doi.org/10.1174/113564007780961624

Ruiz-Bikandi, U. y Camps, A. (2007). Corrientes en investigación educativa y formación del profesorado: una visión de conjunto. Cultura y Educación, vol. 19, núm. 2, pp. 105-122. https://doi.org/10.1174/113564007780961606

Schön, D. (1987). La formación de profesionales reflexivos. Hacia un nuevo diseño de la enseñanza y el aprendizaje en las profesiones. Barcelona: Paidós.

Secretaría de Desarrollo Social (Sedesol) (2013). Catálogo de localidades. Ciudad de México, México. http://www.microrregiones.gob.mx/catloc/contenido.aspx?refnac $=240550089$

Secretaría de Educación Pública (SEP) (2017). Aprendizajes clave para la educación integral. Plan y programas de estudio para la educación básica. México. https://www.planyprogramasdestudio.sep.gob.mx/descargables/APRENDIZAJES_CLAVE_PARA_LA_EDUCACION_INTEGRAL.pdf

Serrano, R. (2010). Pensamiento del profesor: un acercamiento a las creencias y concepciones sobre el proceso de enseñanza-aprendizaje en la educación superior. Revista de Educación, vol. 352, pp. 267-287. http://www.revistaeducacion.educacion.es/re352/re352_12.pdf

Sistema de Información y Gestión Educativa (2018). Consulta de escuelas. Ciudad de México: SEP. https://www.siged.sep.gob.mx/SIGED/escuelas.html

Stenhouse, L. (1982). The conduct, analysis and reporting of case study in educational research and evaluation. En R. McCormick (ed.). Calling education to account (pp. 261-73). Londres: Heinemann.

Rebolledo, V. y Torres, R. (2019). Estado del arte de la educación rural en México (2004-2014). México: Universidad Iberoamericana-Ciudad de México. 